\title{
Searching for threshold shifts in spawner-recruit data
}

\author{
James E. Garvey, Russell A. Wright, and Elizabeth A. Marschall
}

\begin{abstract}
Relationships between spawning fish $(S)$ and surviving offspring (recruits, $R$ ) are typically assumed to be continuous and nonlinear. However, $R$ may change abruptly with small changes in $S$ if population-, community-, or ecosystemscale processes trigger low adult reproduction and cause populations to shift abruptly to regimes of low recruitment. We simulated $R$ with low mean and variation below a known $S$ threshold and high mean and variation of $R$ above it. We compared simulations with published $S-R$ relationships. For all data, we fit a conventional Ricker-type $S-R$ model, a logistic depensatory model, and also searched for an $S$ breakpoint with a nonparametric test. The Ricker and logistic models often fit discontinuous simulated data. The nonparametric test found the $S$ threshold in simulated data, although its accuracy depended on underlying distributions. The Ricker and logistic models and the nonparametric test identified apparent relationships within published data, sharing common results in $<50 \%$ of the data sets. Although population models often assume continuous relationships, discontinuous threshold changes in $R$ with small changes in $S$ may occur. Identification of the conditions that reproductive state changes abruptly in fish populations may be necessary to develop risk-averse regulatory policies.
\end{abstract}

Résumé : On assume généralement que les relations entre les poissons reproducteurs $(S)$ et les rejetons survivants (recrues, $R$ ) sont continues et non linéaires. Cependant, $R$ peut changer abruptement à la suite de petites modifications de $S$ si les processus qui opèrent à l'échelle de la population, de la communauté ou de l'écosystème déclenchent une reproduction adulte faible et forcent les populations à passer rapidement dans un régime de recrutement faible. Nous avons fait des simulations dans lesquelles $R$ possède une moyenne et une variation faibles sous un seuil connu de $S$ et une moyenne et variation élevées au-dessus du seuil. Nous avons comparé nos simulations avec des relations $S-R$ de la littérature. Sur l'ensemble des données, nous avons ajusté un modèle $S-R$ classique de type Ricker et un modèle logistique à effet Allee et avons recherché un point de rupture de $S$ avec un test non paramétrique. Le modèle de Ricker et le modèle logistique s'ajustent souvent aux données simulées discontinues. Le test non paramétrique a trouvé le seuil de $S$ dans les données simulées, bien que la précision dépende des distributions sous-jacentes. Le modèle de Ricker, le modèle logistique et le test non paramétrique ont identifié des relations apparentes dans les données publiées, obtenant des résultats communs dans $<50 \%$ des ensembles de données. Bien que les modèles démographiques présupposent souvent des relations continues, il peut se produire chez $R$ des discontinuités et des seuils à cause de petits changements de $S$. Il peut être nécessaire d'identifier les conditions sous lesquelles l'état reproductif des populations de poissons change abruptement afin de mettre sur pied des politiques de réglementation qui minimisent les risques.

[Traduit par la Rédaction]

\section{Introduction}

Understanding how fisheries respond to harvest requires sound information about population dynamics in the face of complex and perhaps counterintuitive underlying processes. Managing these complex systems often involves forecasting the density of fish recruiting to the fishery to set production

Received 24 March 2008. Accepted 18 December 2008.

Published on the NRC Research Press Web site at cjfas.nrc.ca on 10 February 2009.

J20479

J.E. Garvey. ${ }^{\mathbf{1}}$ Fisheries and Illinois Aquaculture Center, Department of Zoology, and Center for Ecology, Southern Illinois University, Carbondale, IL 62901-6511, USA.

R.A. Wright. Department of Fisheries and Allied Aquacultures, Auburn University, Auburn, AL 36849, USA.

E.A. Marschall. Aquatic Ecology Laboratory, Department of Ecology, Evolution, and Organismal Biology, The Ohio State University, Columbus, OH 43212-1156, USA.

${ }^{1}$ Corresponding author (e-mail: jgarvey@ siu.edu). expectations and derive harvest limits (Ricker 1975). Given that adult fish are typically targeted for harvest, it is important to generate relationships between the density of adult spawners and the number of surviving offspring produced to determine the escapement needed to sustain populations. These relationships often are fitted with continuous functional models (e.g., classic Ricker or Beverton-Holt curves or nonlinear regression models) that depend on assumptions about continuous underlying population mechanisms, such as compensation and depensation.

We suggest that fitting continuous functional models to spawner-recruit relationships may not always be appropriate. Rather, discontinuous processes may be at play, contributing to rapid, possibly threshold shifts in reproductive output as a function of adult density, ultimately leading to regime shifts within fish assemblages (Steele and Henderson 1984; Collie et al. 2004; Schroder et al. 2005). At some region of low spawner densities, low recruit density may occur (Fig. 1; Holling 1973). Above this region, another regime of high but possibly more variable recruitment may exist (Fig. 1). This occurs because the number of offspring 
Fig. 1. Conceptual stock-recruitment scenario in which two recruitment regime states occur. Each point is a hypothetical annual sample from a population. The vertical line is the spawner or egg density $(S)$ at which a two-dimensional Kolmogorov-Smirnov (2DKS) test finds the point of greatest difference in recruit production $(R)$. Below some "region" of spawner abundance, the stable, equilibrium, recruit abundance is very low. Above this region, potential average recruitment is high, but stochastic environmental conditions create more variability. The 2 DKS will identify the region of spawner densities where expected recruits produced shift between these two regimes. Two horizontal mean lines can be fitted through these data to the left and right of the breakpoint. A logistic or Ricker model also may fit this relationship, although the underlying distribution is discontinuous.

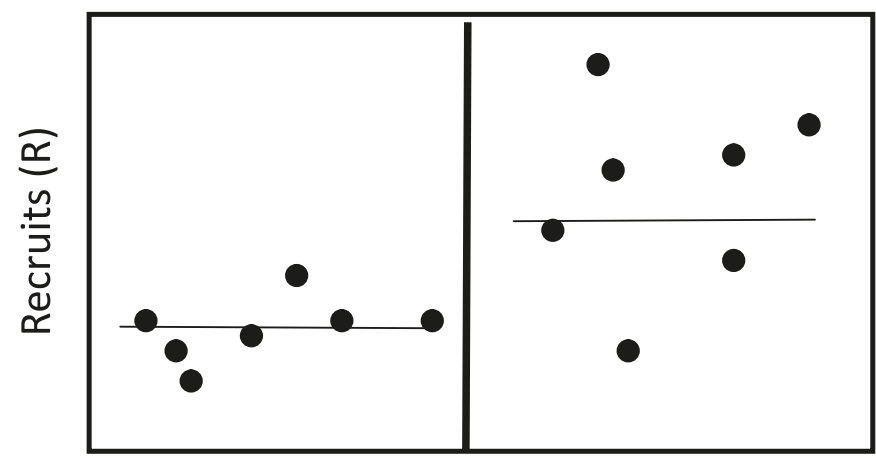

Spawners or eggs (S)

produced is no longer limited by adults and rather is primarily affected by external processes (Leggett and DeBlois 1994; Myers 2002). In other words, ecological release from the limited factor of hatchling production occurs and some other limiting factor (or suite of factors) is at play.

Some populations may have inherent characteristics that make them vulnerable to threshold shifts between low and high recruitment (Fig. 1). Populations may contain phenotypes with unique life histories (e.g., alternative reproductive stable strategies, Gross 1991) that affect reproductive behavior and subsequent recruitment. It is plausible that declining densities of adults may cause rapid changes in the frequency of reproductive phenotypes (e.g., earlier maturation and lower fecundity, Jennings and Philipp 1992) that subsequently result in shifting recruitment regimes (Conover and Munch 2002). In harvested populations, the behavior of fish and their fishers may change abruptly as adults decline (e.g., both may become aggregated, thereby increasing fishing pressure), again causing rapid shifts toward low recruitment (Post et al. 2002). These mechanisms are often considered depensatory because the reproductive output of individual fish declines rather than increases as population density declines.

From a community perspective, it is common for the outcome of predator and prey interactions to depend on life stage (e.g., intraguild interactions, Polis and Holt 1992; Olson et al. 1995). Early life stages of predators and prey may compete, with young prey being superior competitors; adult prey also may consume young predators. If adult predator densities are low and cannot control prey recruitment, then early life stages of prey dominate and suppress predator dominance by reducing predator recruitment (Walters and
Kitchell 2001). These types of interactions create stable states of low predator density when adult predator densities decline to some threshold region (Bampfylde and Lewis 2007). A classic example is the bluegill (Lepomis macrochirus) crowded state that often occurs in small North American lakes, in which small, dense bluegill populations control recruitment of their primary predator, largemouth bass $(\mathrm{Mi}$ cropterus salmoides) (Flickinger et al. 1999).

Ecosystem feedbacks also may cause abrupt shifts in recruitment. Spawning adults may modify their environment in ways that enhance the success of their recruits, such as releasing nutrients from their carcasses after spawning (Naiman et al. 2002). Below some threshold density, adults may no longer provide sufficient environmental conditions to enhance community conditions (i.e., primary and secondary production) that promote survival of their offspring. Again, the result may be a rapid shift to low recruitment. Once the ecosystem has reached a state of low, externally derived subsidies, it may be difficult for it to return to a state of high adult production and increased recruitment without human management (Budy et al. 1998) and ample time for recovery.

We explored whether different recruitment regimes may plausibly exist within fish populations as an alternative to continuous relationships by first simulating expected patterns based on simple assumptions about the production of recruits at spawner densities at which recruitment regime states may change. We treated these spawner densities as threshold random variables ranging from invariant to highly variable, because regimes of recruit production likely vary among years and systems, depending on factors suppressing recruitment at low spawner densities and density-independent factors that affect adult recruitment success at high spawner densities. We then compared these simulated distributions with published spawner-recruit relationships. For both the simulated and actual data sets, we used both continuous models and discontinuous statistical tests ( $i)$ to determine whether such apparently discontinuous recruit regimes are common and may be mistaken for continuous relationships, (ii) to hypothesize about underlying processes, and (iii) to assess whether identifying purported spawner thresholds and related recruitment regimes is useful for the management and conservation of fisheries.

\section{Materials and methods}

We used computer simulations to generate normal, random distributions of spawner $(S)$ and recruit $(R)$ bivariate pairs, with the $R$ regime state (i.e., its distribution) depending on the threshold spawner value $\left(S_{\mathrm{TH}}\right)$. Each negative, randomly generated variable was discarded and replaced with the next positive value. In all simulations, if $S=0$, then $R=0$. The distribution of $S$ values in each simulation had a mean of 100 and a standard deviation (SD) of 100. Thus, small and large values of $S$ were less common than those near 100 . We treated $S_{\mathrm{TH}}$ as a normally distributed random variable in all simulations, with its mean value depending on the modeling scenario (see below). For each scenario, $S_{\mathrm{TH}}$ variation was $\mathrm{SD}=0,10,50,75$, and 100 . Thus, for simulations in which $S_{\mathrm{TH}}$ varied, a unique value of $S_{\mathrm{TH}}$ was generated for each $S, R$ pair. Each simulation within a 
scenario generated $100 S, R$ pairs, with 10 simulations per threshold $\left(S_{\mathrm{TH}}\right)$ variation category. Thus, each simulated data set corresponded to 100 years of cohort production within a population, with each modeling scenario having 10 replicate populations.

We assumed that the variance and mean of recruits was greater for $S>S_{\mathrm{TH}}$. Thus, the mean and variance in $R$ depended on location relative to $S_{\mathrm{TH}}$. Below $S_{\mathrm{TH}}$, values of $R$ were generated with a mean $=0$ and $\mathrm{SD}=10$. Hence, below $S_{\mathrm{TH}}$, small values of $R$ were common and large values rare, which would be expected if recruits were constrained by a strong depensatory-like effect. Above $S_{\mathrm{TH}}$, the mean and variation for $R$ were identical to that of $S$ (i.e., both mean and SD $=100$ ), as might be expected when recruits are unlimited and density-independent mechanisms predominate (i.e., ecological release is occurring).

The position of $S_{\mathrm{TH}}$ relative to the mean of the normally distributed $S$ values might affect the outcome of simulations. This is because the highest density of $S, R$ pairs generated within each simulation likely occurred near the mean $S$, affecting statistical power to detect a threshold effect. Within each simulation, we generated distributions with one of two $S_{\mathrm{TH}}$ mean values. In one case, mean $S_{\mathrm{TH}}=50$ was lower than the mean $S$ of 100 , and thus $S<S_{\mathrm{TH}}$ occurred relatively infrequently. In another set of simulations, we set the mean $S_{\mathrm{TH}}=100$, which was the same as the mean of the $S$ values, causing $S<S_{\mathrm{TH}}$ to occur more commonly.

To compare our simulated $S-R$ relationships with actual data, we acquired 60 summary data sets from a Web site formerly maintained by Ransom A. Myers at Dalhousie University (Halifax, Nova Scotia, Canada; www.mscs.dal.ca/ $\sim$ myers/welcome.html). All of these data sets contained at least 11 years of spawner and recruit abundance pairs and represented a diverse array of taxa (Appendix A, Table A1).

For all data sets, we attempted to fit functional relationships using two models. The first of these is a Ricker-type model (Ricker 1975):

$$
R=S e^{a\left(1-\frac{S}{b}\right)}
$$

in which $a$ and $b$ were estimated with linear regression with a multiplicative error term of $e^{w}$ where $w$ is normally distributed with a mean of 0 . We used the model transformed into its linear form

$$
\ln \left(\frac{R}{S}\right)=a-\left(\frac{a}{b}\right) S
$$

(PROC REG, SAS Institute Inc. 2003); this model captures potential downward inflections in $R$ at high densities of $S$ (Ricker 1975). Given that depensation may suppress densities of recruits at low spawner densities (i.e., creating a sigmoidal shape), we also fit these data to a logistic function

$$
R=\frac{R_{\max } R_{0} \mathrm{e}^{a S}}{R_{\max }+R_{0}\left(\mathrm{e}^{a S}-1\right)}
$$

in which $R_{0}$ is an intercept, $R_{\max }$ is the theoretical maximum recruit density, and $a$ is a constant. These models were fit to data using iterative nonlinear regression with error estimated from residuals (PROC NLIN, SAS Institute Inc. 2003). All regression models were considered significant at $p<0.05$.
In addition to fitting these data sets to functional models, a nonparametric, two-dimensional Kolmogorov-Smirnov (2DKS) test was used to locate potential $S_{\mathrm{TH}}$ densities where purported recruit regimes shifted from low and invariant to high and variable (Fasano and Franceschini 1987; Garvey et al. 1998). This test identifies the point $\left(S^{*}, R^{*}\right)$ within a bivariate (i.e., $S, R)$ distribution in which the distribution of points among the quadrants formed with $S^{*}, R^{*}$ at the center differs the most from the expected distribution that arises when all combinations of $S$ and $R$ are equally likely. This point of maximum difference (i.e., that which generated the maximum value of the test statistic, $D_{\mathrm{BKS}}$ ) corresponds to a simulated threshold breakpoint, in which variation of the dependent variable changes from constrained to relatively unconstrained at a simulated threshold point (Fig. 1; Garvey et al. 1998). In other words, the test found the maximum change in variation in the data set rather than a functional change between the two variables. If a functional relationship is underlying the bivariate relationship, then the maximum change occurs at the median value of $S$. The test appears to be robust to small sample sizes (Garvey et al. 1998).

Each simulated and actual data set was analyzed using the 2DKS test, where the $D_{\mathrm{BKS}}$ test statistics generated for each bivariate point were calculated and compared with those for 5000 rerandomized distributions. A $p$ value for each test was calculated as the proportion of rerandomized data sets that produced a $D_{\text {BKS }}$ larger than the actual data set (see Garvey et al. 1998). The smallest $p$ value was associated with the maximum $D_{\mathrm{BKS}}$ and associated $S, R$ pair $\left(S^{*}, R^{*}\right)$ for each simulated data set. We calculated the mean and standard error of $S$ values associated with each maximum $D_{\mathrm{BKS}}$ value within each simulation set $(N=10)$, which we hypothesized reflected the true $S_{\mathrm{TH}}$ values that occurred between regimes of low plus invariant versus high plus variable recruit abundance.

\section{Results}

Even though the simulations had no underlying functional assumptions, patterns could sometimes be represented with Ricker and logistic models, although the fits of the models varied. When the mean $S_{\mathrm{TH}}=50$, Ricker fits were significant $(p<0.05)$ for only 6 of the 10 data sets when $S_{\mathrm{TH}}$ was invariant and 0 of 10 data sets when $S_{\mathrm{TH}}$ was highly variant with $\mathrm{SD}=100$ (see Fig. 2 for example distributions). When the mean $S_{\mathrm{TH}}=100$, Ricker fits also did not fit the simulated data well (Fig. 2). In contrast, for both mean values of $S_{\mathrm{TH}}$ in simulations, the logistic fits were poor when $S_{\mathrm{TH}}$ was invariant (Figs. $2 f, 2 g$ ), but improved as $S_{\mathrm{TH}}$ increased in variance (Fig. 2; 75\% fit across all simulations). The abrupt "knife-edge" change in recruit abundance at low variation in $S_{\mathrm{TH}}$ apparently prevented logistic model fits (e.g., Figs. $2 f, 2 g$ ).

The $S_{\mathrm{TH}}$ values associated with the maximum $D_{\mathrm{BKS}}$ statistics in the 2DKS differed in their ability to match the true location of $S_{\mathrm{TH}}$ in simulations (Fig. 2). The $S_{\mathrm{TH}}$ mean relative to the mean of $S$ in each simulated population affected the predicted value (Fig. 3). When the mean $S_{\mathrm{TH}}$ was 50 , less than the expected $S$ of 100, the 2DKS overestimated the true threshold value, with the bias increasing as the var- 
Fig. 2. Randomly chosen example distributions of spawner abundance $(S)$ and recruit abundance $(R)(N=100$ per panel; nine additional simulations were conducted for each scenario). In all of these simulations, mean and variance of $R$ was small below the spawner threshold $\left(S_{\mathrm{TH}}\right)$ and high above it. In panels $a-e$, the mean $S_{\mathrm{TH}}=50$ and in panels $f-j$, mean $S_{\mathrm{TH}}=100$. The diamond on each panel depicts the predicted $S_{\mathrm{TH}}$ from a nonparametric 2DKS test $(p<0.05)$. The broken curve fitted through each relationship derives from a significant $(p<$ $0.05)$ Ricker model, if one occurred. Solid curves are significant logistic model fits. ( $a$ and $f)$ Standard deviation $(\mathrm{SD})$ of $S_{\mathrm{TH}}=0 ;(b$ and $g) \mathrm{SD}=10 ;(c$ and $h) \mathrm{SD}=50 ;(d$ and $i) \mathrm{SD}=75 ;(e$ and $j) \mathrm{SD}=100$.

$$
S_{\mathrm{TH}}=50
$$

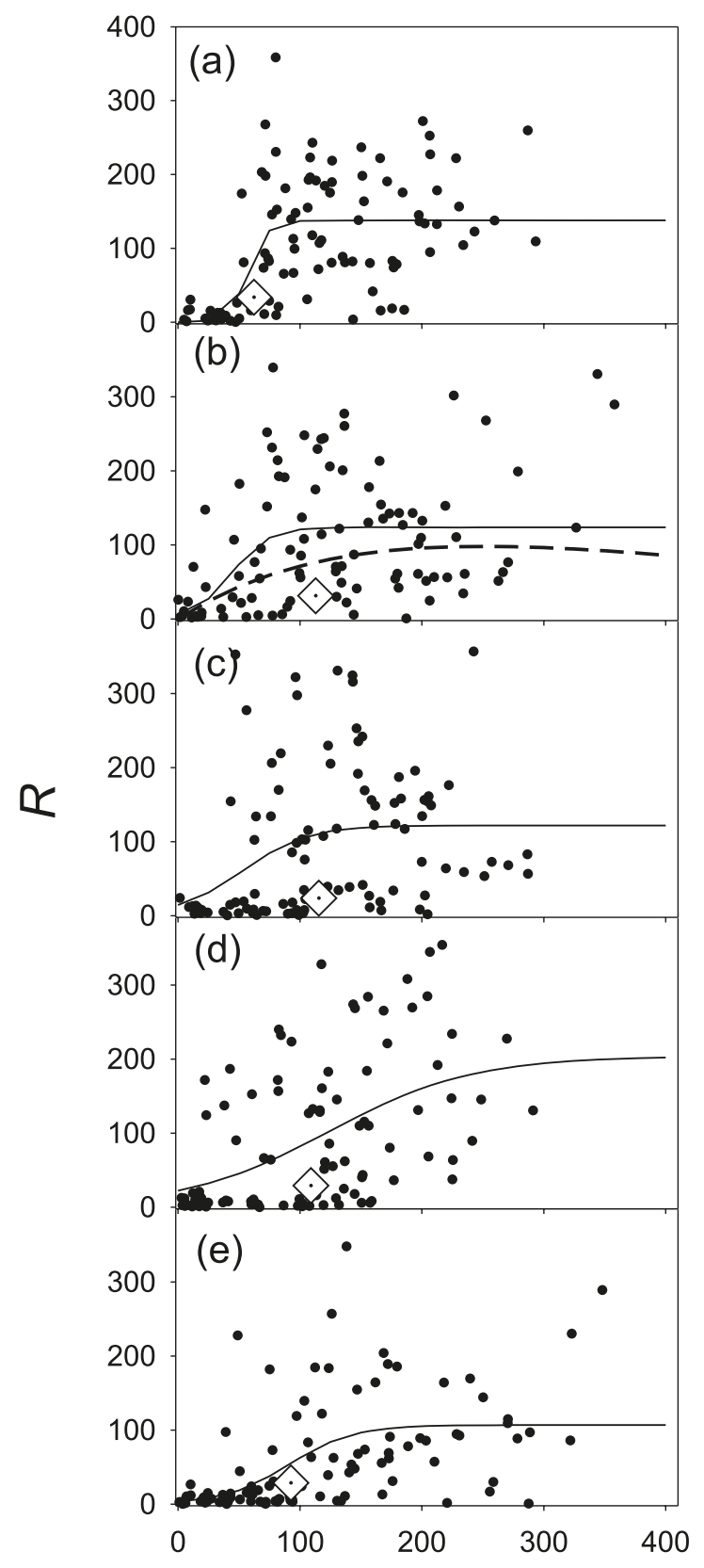

$$
S_{\mathrm{TH}}=100
$$

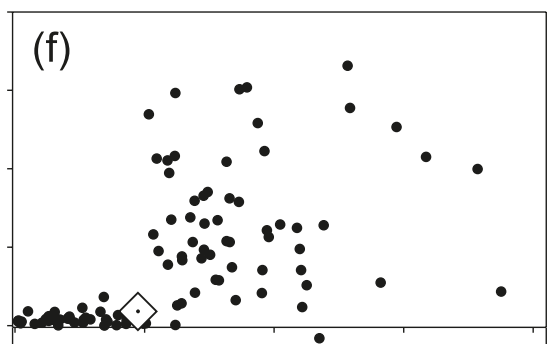

(g)

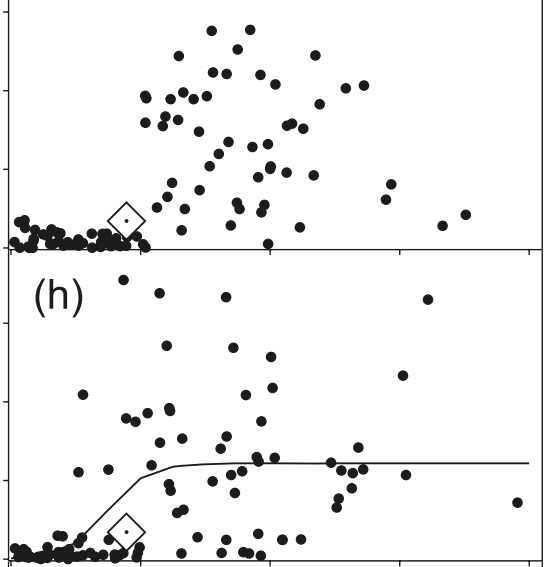

(i)

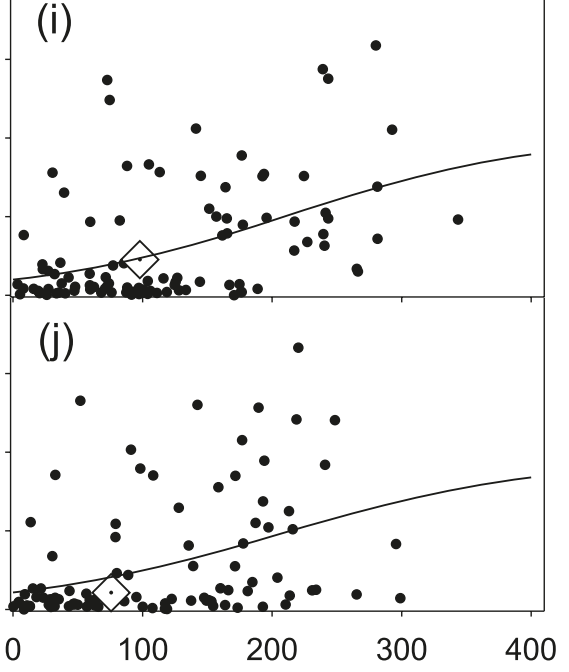

$S$

iance of $S_{\mathrm{TH}}$ increased (Figs. $2 a-2 e$, Fig. 3). This bias was likely due to the relative distribution of points generated around $S_{\mathrm{TH}}$ and its effect on the test's ability to identify the simulated change (i.e., fewer points occurred to the left of the $S_{\mathrm{TH}}$ ). Biased estimates did not occur when $S_{\mathrm{TH}}$ was 100 , the same as the expected $S$ (Figs. $2 f-2 j$, Fig. 3 ).
Patterns within published $S-R$ data sets were diverse (Fig. 4). The Ricker model produced significant fits through $58 \%$ of the 60 data sets, whereas the logistic model fit $11 \%$ of the populations. The 2DKS test found significant apparent breakpoints in $45 \%$ of the data sets. The Ricker and 2DKS jointly found significant relationships in $33 \%$ in the subset 
Fig. 3. Mean \pm standard error of predicted threshold spawner density $\left(S_{\mathrm{TH}}\right)$ that produced the largest test statistic in each simulation $(N=10$ simulations per mean) as a function of variation in the true $S_{\mathrm{TH}}$ values. The solid horizontal line is $S_{\mathrm{TH}}=50$ (predicted means, open circles), and the broken line represents $S_{\mathrm{TH}}=100$ (solid circles).

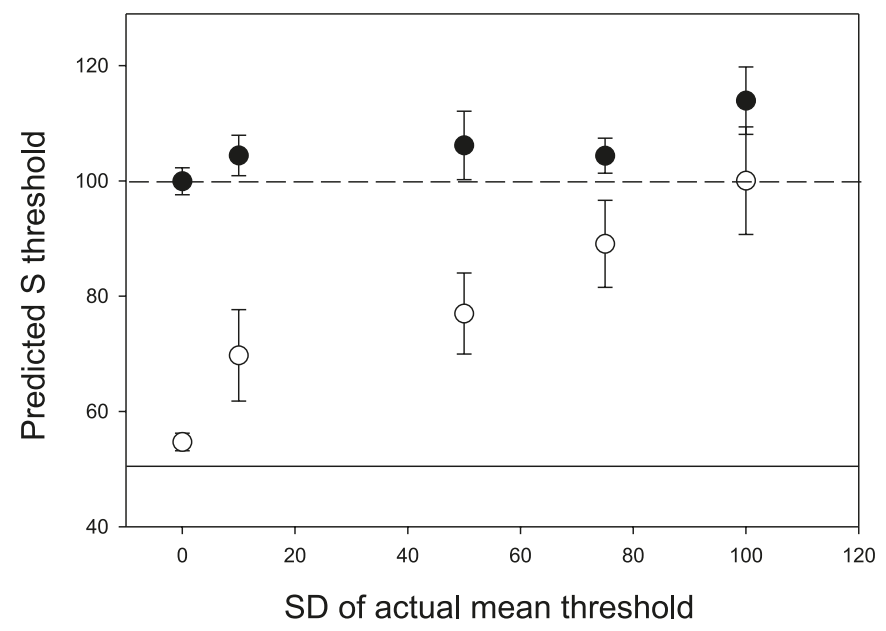

of data sets in which one test found a relationship. The logistic and 2DKS shared significant results for $55 \%$ of the significant data sets.

Breakpoints identified by the 2DKS appeared to locate meaningful changes in variation that could be qualitatively categorized in all of the example data sets (Fig. 4). For alewife (Alosa pseudoharengus) and capelin (Mallotus villosus) examples, $R$ was low below the purported $S_{\mathrm{TH}}$; the average $R$ increased past the breakpoint (Figs. $4 a, 4 b$ ). A significant Ricker relationship also could be fit to these data (Figs. $4 a$, 4b). A logistic model fit the capelin data, but the fit was poor (Fig. 4b). In bluefin tuna (Thunnus thynnus), Atlantic cod (Gadus morhua), and Atlantic herring (Clupea harengus) $S-R$ distributions, the mean and variance in $R$ was constrained below the purported $S_{\mathrm{TH}}$ (Figs. $4 c-4 e$ ). Above the $S$ breakpoint, $S$ and $R$ were positively related for these species (Figs. 4c-4e). For herring, both Ricker and logistic models could be fit to the data (Fig. 4e). Both mean and variation of recruits were constrained below the $S_{\mathrm{TH}}$ for red king crab (Paralithodes camtschaticus) and lake whitefish (Coregonus clupeaformis) (Figs. 4f, 4g). A Ricker fit occurred for the red king crab data set and a logistic fit for the lake whitefish data (Figs. 4f, 4g). For pink salmon (Oncorhynchus gorbuscha), only a breakpoint could be identified (Fig. 4h). In most of these example data sets, the apparent clustering of recruits at low densities below the $S$ breakpoint (notably Figs. $4 c, 4 d, 4 e, 4 f, 4 g$ ) was a pattern similar to that generated by our discontinuous simulations (Fig. 2).

\section{Discussion}

Conventional wisdom holds that smooth, continuous functions underlie relationships between adults and offspring production in populations and that these functions ultimately shape population dynamics. Conversely, our results show that it is plausible that rapid, discontinuous shifts in reproductive output at some threshold region of adult density affect recruitment success. As our simulations and some of the actual data sets demonstrated, in the absence of underlying mechanistic data (e.g., experimentally derived), it may be difficult to ascertain under what circumstances the assumption of continuous versus discontinuous processes is appropriate.

Assumptions about underlying ecological relationships have important implications for managing risk (Walker and Meyers 2004). Fisheries management strategies often depend on setting allowable harvest to permit sufficient escapement of spawners. These surviving adults then live on to generate sustainable and strong year classes of recruits. Traditionally the spawner to recruit relationship has been characterized with various continuous functional models that seek to find the appropriate target adult density that ensures high recruitment in the future, with limited success (Hilborn et al. 1995). A possible reason for failure is that these models assume that recruitment within populations exists along a continuum of equilibrium states across a range of adult densities, creating predictable management scenarios. However, if populations have discrete stable recruitment regime states depending on regions of spawner density, then assuming that continuous functional relationships apply through the entire data set may generate erroneous management decisions.

Rather than assuming smooth underlying relationships, using tools that identify how adult abundance affects the mean and variation in recruit abundance may be more appropriate. In fact, as our simulations and some of the published data sets suggest, statistical models such as the Ricker, with compensatory assumptions, and the logistic, which incorporates a depensatory-like response at low densities, may find continuous $S-R$ relationships when patterns are in reality driven by abrupt, discontinuous changes in recruitment state. Thus, approaches for finding breakpoints in bivariate data such as the 2DKS and others (e.g., biphasic linear regression, Nickerson et al. 1989; maximum likelihood modeling, Beckage et al. 2007) may be necessary for defining important regime state shifts or identifying abrupt functional changes within fish populations and other ecological systems. Many ecological mechanisms occurring at the population, community, and perhaps ecosystem level may have affected individual reproductive output and caused the abrupt changes.

Although real biological reasons may exist for threshold changes in spawner-recruit relationships, the ability for the statistical test we used (as well as others) to identify the true threshold depends on complex factors, including underlying sampling distributions. Our simulations showed that the $2 \mathrm{DKS}$ test would yield conservatively inaccurate estimates of the true threshold spawning density under specific circumstances. Although this may lead to risk-averse management, it also may result in economically costly limitations to fishery yield. Thus, in addition to using statistical tools to identify putative shifts in spawner-recruit relationships, our results underscore the need to understand causal mechanisms.

For other data sets, underlying relationships between spawners and recruits may have been continuous, rendering the assumption of a threshold change false, even if the 2DKS identified a breakpoint. In these continuous relationships, the 2DKS was simply identifying some point of central tendency in the bivariate distribution (i.e., the median); 
Fig. 4. Spawner $(S)$ and recruit $(R)$ relationships for eight example fisheries out of 60 (Appendix A, Table A1). Panels correspond to data in Appendix A: (a) alewife (Alosa pseudoharengus, data set 1), (b) capelin (Mallotus villosus, data set 8), (c) bluefin tuna (Thunnus thynnus, data set 6), (d) Atlantic cod (Gadus morhua, data set 13), (e) Atlantic herring (Clupea harengus, data set 27), (f) red king crab (Paralithodes camtschaticus, data set 48), (g) lake whitefish (Coregonus clupeaformis, data set 35 ), and (h) pink salmon (Oncorhynchus gorbuscha, data set 43). The vertical line in each panel depicts the $S$ that produced the maximum difference in each 2DKS test. The broken (Ricker) and solid (logistic) curves fitted through each relationship derive from a significant $(p<0.05)$ regression model, if one occurred. Axes values differ among data sets and are not depicted.
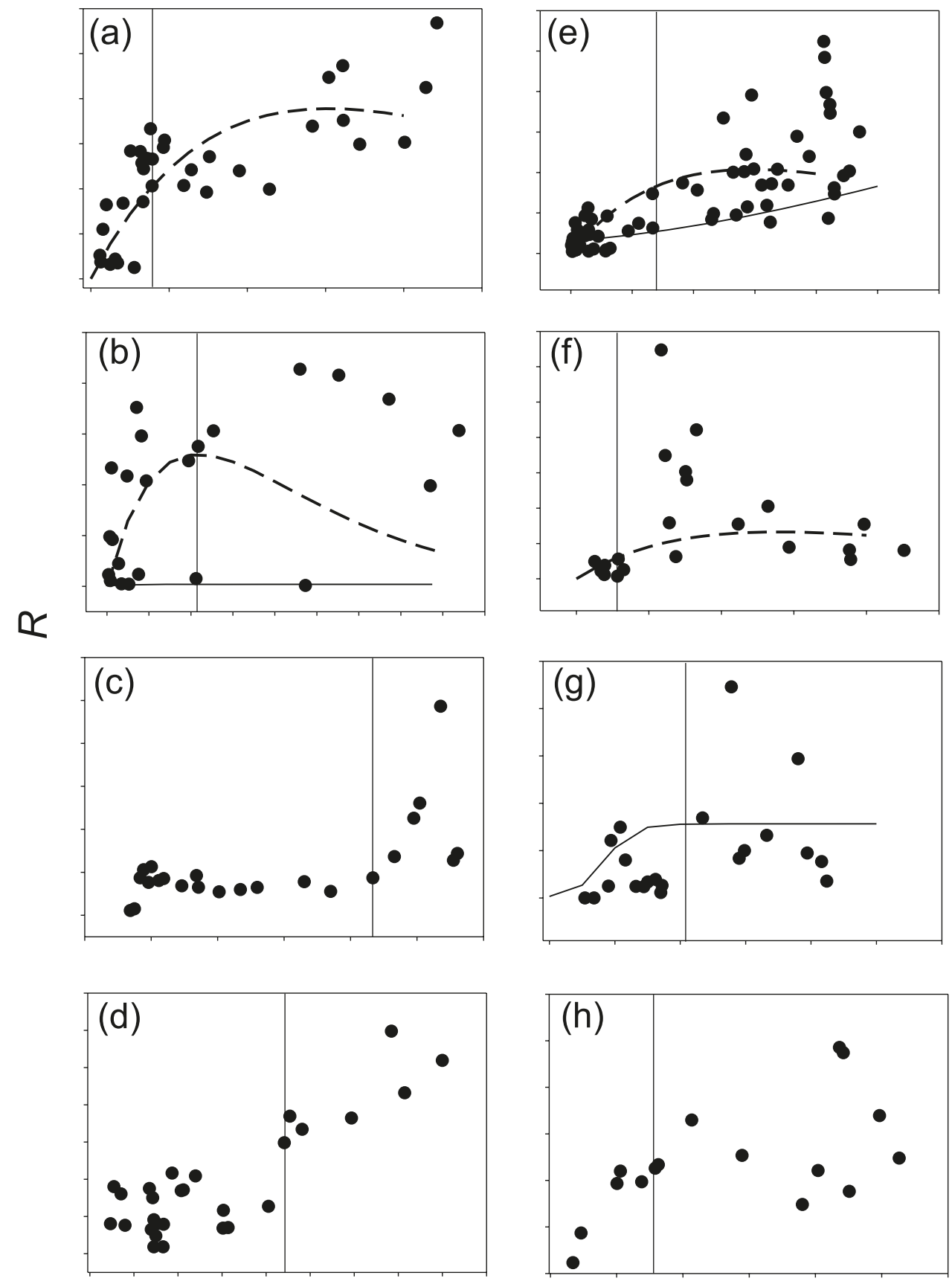

S

the spawner-recruit patterns likely were nonlinear because of density-dependent feedbacks within the population (Myers 2002), with no abrupt shift in recruits. A candidate from our example data sets may have been the alewife pattern, as identified by its strong Ricker model fit. At low den- sities of adults, reduced intraspecific competition may have improved adult condition and enhanced birth rates (i.e., classic compensation). As adult abundance ascended toward some purported carrying capacity, birth rates declined (Myers 2002), causing recruit production to decelerate. Off- 
spring survival also may have declined as intracohort competition (Rettig and Mittelbach 2002) or predation (Forney 1976) increased.

It is also possible that continuous relationships may apply across only a subset of spawner densities and that tests such as the 2DKS find this transition. For example, the apparent decline in mean $R$ past some intermediate density of $S$ in some of the populations (particularly for red king crab) may be explained by density-dependent responses at high $S$, which we did not incorporate in our simulations. Similarly, the linear increase in recruits above the purported spawner breakpoint for Atlantic herring suggests a lack of compensatory feedback and perhaps a lognormal increase in variation of recruits produced, which again were not incorporated in our simulations.

When they occur, putative threshold spawner densities that affect recruitment state within a fishery may change among years and populations. Our simulations demonstrated that this variation might cause discontinuous relationships between spawners and recruits to appear to be smooth if the spawner threshold varies markedly. For example, behavior of fishers and their impact on spawners may vary among years depending on factors affecting fishing profitably and success (Bettoli et al. 2007). Other factors such as climate, food quality, and reproductive habitat that vary among years and populations may influence the point at which recruitment is constrained by adult abundance. Identifying variability around the average spawner threshold would allow us to bracket the region of spawner densities that fundamentally different recruitment mechanisms (e.g., biotic versus abiotic) are at play. Appropriate modeling and research may then be directed toward identifying underlying processes (Muradian 2001; Bestelmeyer 2006).

An unfortunate characteristic of all our example relationships is that spawner abundance declined to such a point that the mean and variation in recruits were constrained, and presumably these populations reached a state of low spawner and recruit density. Thus, to identify such relationships, either environmental conditions or harvest must have been sufficiency deleterious to deplete adult densities and perhaps cause populations to fall into an apparent, lowrecruitment regime state. Obviously, allowing recruits to decline to identify the critical spawner threshold is not a desirable management scenario. Further, recovery of these populations to high recruitment states may be difficult. Once populations have reached a low recruitment state, lags may exist in the response of recruitment to increasing spawner densities and favorable external factors. Within populations, genotypes that favor reproductive phenotypes with high inherent reproductive output (late maturation, high fecundity) may be rare and take time to increase in populations as adult densities rise (Jennings et al. 1997; Walsh et al. 2006). At the community level, an increase in sympatric predators and competitors at low recruit abundance may suppress the ability for recruit production to rapidly increase if spawner densities increase past the purported spawner threshold (Walters and Kitchell 2001). At the ecosystem scale, adult-driven feedbacks to food webs may be absent, preventing recruitment from successfully occurring.

It is our hope that the 2DKS test and others that detect breakpoints in bivariate data might be used to identify apparently discontinuous relationships and potential recruitment regimes in existing distributions. It would drive mechanistic research into the nature of apparent adult reproductive thresholds and allow managers to avoid these conditions in other populations in which such possible regime shifts have not yet occurred (Post et al. 2002). In other words, the goal would be to keep populations from reaching regions of spawner densities that cause regimes of low recruitment potential. As a heuristic tool, the ability for the 2DKS test and others to identify inflections may allow researchers to design models or experiments to understand under what conditions internal dynamics within populations versus external environmental factors drive the production of cohorts.

\section{Acknowledgements}

Thanks are extended to the late Ransom Myers for providing a wonderful repository of spawner-recruit data. We would have liked to have the opportunity to discuss this manuscript with him. Three thoughtful reviewers transformed the data and the resulting manuscript. A copy of the 2DKS program can be found at www.science.siu.edu/ zoology/garvey/2dks.html.

\section{References}

Bampfylde, C.J., and Lewis, M.A. 2007. Biological control through intraguild predation: case studies in pest control, invasive species and range expansion. Bull. Math. Biol. 69: 1031-1066. doi:10.1007/s11538-006-9158-9. PMID:17308949.

Beckage, B., Joseph, L., Belisle, P., Wolfson, D.B., and Platt, W.J. 2007. Bayesian change-point analyses in ecology. New Phytol. 174(2): 456-467. doi:10.1111/j.1469-8137.2007.01991.x. PMID: 17388908 .

Bestelmeyer, B.T. 2006. Threshold concepts and their use in rangeland management and restoration: the good, the bad, and the insidious. Restor. Ecol. 14(3): 325-329. doi:10.1111/j.1526-100X. 2006.00140.x.

Bettoli, P.W., Scholten, G.D., and Reeves, W.C. 2007. Fisheries management - protecting paddlefish from overfishing: a case history of the research and regulatory process. Fisheries, 32: 390397. doi:10.1577/1548-8446(2007)32[390:PPFOCH]2.0.CO;2.

Budy, P., Luecke, C., and Wurtsbaugh, W.A. 1998. Adding nutrients to enhance the growth of endangered sockeye salmon: trophic transfer in an oligotrophic lake. Trans. Am. Fish. Soc. 127(1): 19-34. doi:10.1577/1548-8659(1998)127<0019:ANTETG>2.0. $\mathrm{CO} ; 2$.

Collie, J.S., Richardson, K., and Steele, J.H. 2004. Regime shifts: can ecological theory illuminate the mechanisms? Prog. Oceanogr. 60: 281-302. doi:10.1016/j.pocean.2004.02.013.

Conover, D.O., and Munch, S.B. 2002. Sustaining fisheries yields over evolutionary time scales. Science (Washington, D.C.), 297: 94-96. doi:10.1126/science.1074085. PMID:12098697.

Fasano, G., and Franceschini, A. 1987. A multidimensional version of the Kolmogorov-Smirnov test. Mon. Not. R. Astron. Soc. 225: $155-170$.

Flickinger, S.A., Bulow, F.J., and Willis, D.W. 1999. Chapter 21: Small impoundments. In Inland fisheries management in North America. 2nd ed. Edited by C.C. Kohler and W.A. Hubert. American Fisheries Society, Bethesda, Md. pp. 561-587.

Forney, J.L. 1976. Year-class formation in the walleye (Stizostedion vitreum vitreum) population of Oneida Lake, New York, 1966-1973. J. Fish. Res. Board Can. 33: 783-792. 
Garvey, J.E., Marschall, E.A., and Wright, R.A. 1998. From star charts to stoneflies: detecting relationships in continuous bivariate data. Ecology, 79(2): 442-447.

Gross, M.R. 1991. Salmon breeding behavior and life history evolution in changing environments. Ecology, 72: 1180-1186. doi:10.2307/1941091.

Hilborn, R., Walters, C.J., and Ludwig, D. 1995. Sustainable exploitation of renewable resources. Annu. Rev. Ecol. Syst. 26: 45-67. doi:10.1146/annurev.es.26.110195.000401.

Holling, C.S. 1973. Resilience and stability of ecological systems. Annu. Rev. Ecol. Syst. 4: 1-23. doi:10.1146/annurev.es.04. 110173.000245.

Jennings, M.J., Claussen, J.E., and Philipp, D.P. 1997. Effect of population size structure on reproductive investment of male bluegill. N. Am. J. Fish. Manage. 17: 516-524.

Jennings, M.J., and Philipp, D.P. 1992. Reproductive investment and somatic growth rates in longear sunfish. Environ. Biol. Fishes, 35: 257-271. doi:10.1007/BF00001892.

Leggett, W.C., and DeBlois, E. 1994. Recruitment in marine fishes: is it regulated by starvation and predation in the egg and larval stages? Neth. J. Sea Res. 32: 119-134. doi:10.1016/00777579(94)90036-1.

Muradian, R. 2001. Ecological thresholds: a survey. Ecol. Econ. 38(1): 7-24. doi:10.1016/S0921-8009(01)00146-X.

Myers, R.A. 2002. Recruitment: understanding density-dependence in fish populations. In Handbook of fish biology and fisheries. Vol. 1. Edited by P.J.B. Hart and J.D. Reynolds. Blackwell Publishing, Oxford, UK. pp. 123-148.

Naiman, R.J., Bilby, R.E., Schindler, D.E., and Helfield, J.M. 2002. Pacific salmon, nutrients, and the dynamics of freshwater and riparian ecosystems. Ecosystems, 5: 399-417. doi:10.1007/ s10021-001-0083-3.

Nickerson, D.M., Facey, D.E., and Grossman, G.D. 1989. Estimating physiological thresholds with continuous 2-phase regression. Physiol. Zool. 62(4): 866-887.

Olson, M.H., Mittelbach, G.G., and Osenberg, C.W. 1995. Competition between predator and prey: resource-based mechanisms and implications for stage-structured dynamics. Ecology, 76: 1758-1771. doi:10.2307/1940708.

Polis, G.A., and Holt, R.D. 1992. Intraguild predation - the dynamics of complex trophic interactions. Trends Ecol. Evol. 7: 151-154. doi:10.1016/0169-5347(92)90208-S.

Post, J.R., Sullivan, M., Cox, S., Lester, N.P., Walters, C.J., Parkinson, E.A., Paul, A.J., Jackson, L., and Shuter, B.J. 2002. Canada's recreational fisheries: the invisible collapse? Fisheries, 27: 6-17. doi:10.1577/1548-8446(2002)027<0006:CRF>2.0.CO;2.

Rettig, J.E., and Mittelbach, G.G. 2002. Interactions between adult and larval bluegill sunfish: positive and negative effects. Oecologia (Berlin), 130(2): 222-230.

Ricker, W. E. 1975. Computation and intepretation of biological statistics of fish populations. Bull. Fish. Res. Board Can. No. 191.

SAS Institute Inc. 2003. Statistical analysis system. SAS Institute Inc., Cary, N.C., USA.

Schroder, A., Persson, L., and De Roos, A.M. 2005. Direct experimental evidence for alternative stable states: a review. Oikos, 110: 3-19. doi:10.1111/j.0030-1299.2005.13962.x.

Steele, J.H., and Henderson, E.W. 1984. Modeling long-term fluctuations in fish stocks. Science (Washington, D.C.), 224: 985987. doi:10.1126/science.224.4652.985. PMID:17731996.

Walker, B., and Meyers, J.A. 2004. Thresholds in ecological and social-ecological systems: a developing database. Ecology and Society, 9(2): article 3.

Walsh, M.R., Munch, S.B., Chiba, S., and Conover, D.O. 2006. Maladaptive changes in multiple traits caused by fishing: impediments to population recovery. Ecol. Lett. 9: 142-148. doi:10. 1111/j.1461-0248.2005.00858.x. PMID:16958879.

Walters, C., and Kitchell, J.F. 2001. Cultivation/depensation effects on juvenile survival and recruitment: implications for the theory of fishing. Can. J. Fish. Aquat. Sci. 58: 39-50. doi:10.1139/ cjfas-58-1-39.

\section{Appendix A}

Table A1. List of spawner $(S)$ and recruit $(R)$ data used in analyses of patterns with a Ricker model and a nonparametric, two-dimensional Kolmogorov-Smirnov (2DKS) test.

\begin{tabular}{lllll}
\hline No. & Species & Location & $S$ & $R$ \\
\hline 1 & Alosa pseudoharengus & Atlantic Ocean, Damariscotta River & Biomass & Numbers \\
2 & Alosa pseudoharengus & Atlantic Ocean, Saint John River & Biomass & Numbers \\
3 & Alosa pseudoharengus & Atlantic Ocean, Saint John River & Numbers & Numbers \\
4 & Engraulis mordax & Pacific Ocean, California & Biomass & Numbers \\
5 & Alosa sapidissima & Atlantic Ocean, Connecticut River & Numbers & Numbers \\
6 & Thunnus thynnus & West Atlantic & Biomass & Numbers \\
7 & Mallotus villosus & Iceland & Biomass & Index \\
8 & Mallotus villosus & Barents Sea & Biomass & Numbers \\
9 & Mallotus villosus & Barents Sea & Biomass & Index \\
10 & Mallotus villosus & Barents Sea & Biomass & Index \\
11 & Oncorhynchus tshawytscha & Alaska, Blossom River & Numbers & Numbers \\
12 & Oncorhynchus tshawytscha & Alaska, Chickamin River & Numbers & Numbers \\
13 & Gadus morhua & North Atlantic, NAFO 2J3KL & Biomass & Numbers \\
14 & Gadus morhua & North Atlantic, NAFO 3NO & Biomass & Numbers \\
15 & Gadus morhua & North Atlantic, NAFO 3PN4RS2 & Biomass & Numbers \\
16 & Gadus morhua & North Atlantic, NAFO 3Pn4RS & Biomass & Numbers \\
17 & Gadus morhua & North Atlantic, NAFO 3PS & Biomass & Numbers
\end{tabular}


Table A1 (concluded).

\begin{tabular}{|c|c|c|c|c|}
\hline No. & Species & Location & $S$ & $R$ \\
\hline 18 & Gadus morhua & North Atlantic, NAFO 4tvn & Biomass & Numbers \\
\hline 19 & Gadus morhua & North Atlantic, NAFO 4vsw & Biomass & Numbers \\
\hline 20 & Gadus morhua & North Atlantic, NAFO $5 Y 2$ & Index & Index \\
\hline 21 & Gadus morhua & North Atlantic, NAFO 5Z & Biomass & Numbers \\
\hline 22 & Gadus morhua & Baltic Ocean & Biomass & Numbers \\
\hline 23 & Gadus morhua & Baltic Ocean & Biomass & Numbers \\
\hline 24 & Gadus morhua & Iceland & Biomass & Numbers \\
\hline 25 & Gadus morhua & North Sea & Biomass & Numbers \\
\hline 26 & Gadus morhua & North Atlantic & Biomass & Numbers \\
\hline 27 & Clupea harengus & Downs Stock & Biomass & Numbers \\
\hline 28 & Clupea harengus & Georges Bank & Biomass & Numbers \\
\hline 29 & Clupea harengus & Gulf of Maine & Biomass & Numbers \\
\hline 30 & Clupea harengus & Vancouver Island & Biomass & Numbers \\
\hline 31 & Clupea harengus & Alaska & Biomass & Numbers \\
\hline 32 & Clupea harengus & Alaska & Adult eggs & Numbers \\
\hline 33 & Clupea harengus & Vancouver Island (SW) & Biomass & Numbers \\
\hline 34 & Scomberomorus cavalla & Gulf of Mexico & Numbers & Numbers \\
\hline 35 & Coregonus clupeaformis & Lake Huron & Adult eggs & Index \\
\hline 36 & Coregonus clupeaformis & Lake Superior & Biomass & Numbers \\
\hline 37 & Coregonus clupeaformis & Whitefish Bay, Lake Superior & Biomass & Numbers \\
\hline 38 & Scomber scombrus & North Atlantic & Biomass & Numbers \\
\hline 39 & Scomber scombrus & Black Sea & Biomass & Numbers \\
\hline 40 & Brevoortia tyrannus & US Atlantic & Female biomass & Numbers \\
\hline 41 & Brevoortia patronus & Gulf of Mexico & Biomass & Numbers \\
\hline 42 & Engraulis ringens & Peru & Biomass & Numbers \\
\hline 43 & Oncorhynchus gorbuscha & Auke Creek, Alaska & Numbers & Numbers \\
\hline 44 & Oncorhynchus gorbuscha & Bakhura River & Numbers & Numbers \\
\hline 45 & Oncorhynchus gorbuscha & Aristazabal Is., British Columbia & Numbers & Numbers \\
\hline 46 & Oncorhynchus gorbuscha & Bentinck, British Columbia & Numbers & Numbers \\
\hline 47 & Oncorhynchus gorbuscha & Alaska & Numbers & Numbers \\
\hline 48 & Paralithodes camtschaticus & Bristol Bay, Alaska & Biomass & Numbers \\
\hline 49 & Sardinops sagax & California & Biomass & Numbers \\
\hline 50 & Sardinops sagax & Gulf of California & Numbers & Numbers \\
\hline 51 & Sander vitreum & Balsam Lake, Ontario & Index & Index \\
\hline 52 & Sander vitreum & Lake Erie & Index & Index \\
\hline 53 & Sander vitreum & Lake Erie & Numbers & Numbers \\
\hline 54 & Sander vitreum & Lake Erie & Index & Index \\
\hline 55 & Coregonus lavaretus & Lake Constance, Europe & Numbers & Numbers \\
\hline 56 & Theragra chalcogramma & Gulf of Alaska & Biomass & Numbers \\
\hline 57 & Theragra chalcogramma & West Bering Sea & Biomass & Numbers \\
\hline 58 & Pleuronectes ferrugineus & North Atlantic & Biomass & Numbers \\
\hline 59 & Thunnus albacares & Eastern Pacific Ocean & Biomass & Numbers \\
\hline 60 & Thunnus albacares & Indian Ocean & Numbers & Numbers \\
\hline
\end{tabular}

Note: Each data set contains at least 11 years worth of cohort data. 